\title{
Psychopathological Aspects in Children with Epilepsy and Its Contributing Factors: A Cross- Sectional Study from India
}

\author{
Chandrika Azad ${ }^{1}$ (ishal Guglani ${ }^{1}$ Anam Siddiqui ${ }^{1}$ Sukhvinder Singh ${ }^{2}$ \\ ${ }^{1}$ Department of Pediatrics, Government Medical College and \\ Hospital, Chandigarh, India \\ 2 Department of General Medicine, Dr. Harvansh Singh Judge Institute \\ of Dental Sciences, Punjab University, Chandigarh, India \\ Address for correspondence Chandrika Azad, MD, Department of \\ Pediatrics, Government Medical College and Hospital, Chandigarh, \\ India (e-mail: chandrika_azad@yahoo.co.in).
}

J Neurosci Rural Pract 2022;13:301-306.

\begin{abstract}
Keywords

- antiepileptic drugs

- children with epilepsy

- psychopathological problems

Background Children with epilepsy (CWE) are at high risk of psychopathological problems because of neurobiological, social, and treatment factors.

Objectives This study was conducted to estimate the prevalence of psychopathological problems in CWE and their contributing factors.

Methods This cross-sectional study was done in pediatric neurology clinic and outpatient department of a government medical college in Northern India. Children between the ages of 4 and 14 years with intelligence quotient $>70$ were enrolled; for CWE, the criteria were antiepileptic drugs therapy for more than 6 months and for controls it was being free from any chronic illness. Childhood Psychopathology Measurement Schedule (CPMS) was used for assessing psychopathological problems. Results A total of 135 CWE and 70 controls were enrolled, groups were similar in respect of age, gender, socioeconomic status, and family history. CWE group had significantly high mean \pm standard deviation CPMS scores $(13.68 \pm 10.57)$ as compared with controls $(9.75 \pm 7.97)(p<0.0001)$. These scores were particularly high in sectors of low intelligence, conduct disorder, psychotic symptoms, and depression. Academic performance was significantly poor in CWE (39\%) versus controls (6\%) ( $p$ 0.042). Age of onset, duration, type, and etiology of epilepsy had no significant relation with CPMS scores. Polytherapy and treatment with valproate were associated with high CPMS scores ( $p 0.005$ and 0.045).

Conclusion Psychopathological problems are frequently associated with epilepsy in children and antiepileptic drug therapy might contribute to it.
\end{abstract}

\section{Introduction}

Epilepsy is one of the most common neurological diagnoses among all age groups. The prevalence rate for epilepsy in Indian children ranges from 2.02 per 1,000 to as high as 22.2 per $1,000 .{ }^{1}$ Certain type of genetic and symptomatic epilep- sies are found to be specific for the pediatric age group. In the pediatric age group, up to 10 to $20 \%$ epilepsy patients are refractory to treatment. ${ }^{2}$

Children with epilepsy (CWE) have increased risk of developing psychological disorders and educational published online March 2, 2022
DOI https://doi.org/

$10.1055 / \mathrm{s}-0042-1743459$. ISSN $0976-3147$.
(C) 2022. Association for Helping Neurosurgical Sick People. All rights reserved.

This is an open access article published by Thieme under the terms of the Creative Commons Attribution-NonDerivative-NonCommercial-License, permitting copying and reproduction so long as the original work is given appropriate credit. Contents may not be used for commercial purposes, or adapted, remixed, transformed or built upon. (https://creativecommons.org/ licenses/by-nc-nd/4.0/)

Thieme Medical and Scientific Publishers Pvt. Ltd., A-12, 2nd Floor, Sector 2, Noida-201301 UP, India 
problems because of comorbidities, drug effects, and social factors. $^{3-5}$ Poor socioeconomic status is also a powerful factor in mental health. Studies suggest direct correlation between poverty and emotional problems; further, because of financial constraints there are differential availability and treatment modes among various social strata. ${ }^{6}$

We conducted this study to look for psychopathological problems in CWE and factors contributing to it.

\section{Methodology}

This single-center, cross-sectional study was done at the Government Medical College and Hospital, Chandigarh, North India, after getting approval from the Institutional Ethics Committee. It was conducted over a period of 12 months from January 2017 to December 2018.

There were two groups of patients, CWE and controls. CWE were included if they were on antiepileptic drugs (AEDs) for at least 6 months' duration, and for controls, criteria was to be free of any chronic disease. Patients were excluded from either group if consent was denied, intelligent quotient was $<70$, or there was significant physical illness like cerebral palsy, asthma, cardiac problem, significant renal disorders like nephrotic syndrome or chronic renal failure, and endocrinological disorders like diabetes or thyroid disorders requiring prolonged treatment or care.

\section{Sample Size}

Assuming no difference between the two groups, following assumptions were considered, $\alpha$ of 0.05 (two-sided), power $0.8, \mathrm{p} 10.40, \mathrm{p} 2=0.20$, and $\mathrm{n} 2 / \mathrm{n} 1=0.50$, making number of patients in the CWE group 135 and 70 controls.

\section{Study Procedure and Data Collection}

All patients between 4 and 14 years of age coming to the pediatric outpatient department and neurology clinic were screened for potential eligibility. Parents were informed about the purpose of the study and enrolment was done after obtaining written informed consent from either parent and assent from the children ( $>7$ years). Controls were children who came for routine vaccination or minor illnesses but without any chronic disease.

Patient details like age, gender, presenting complaints, previous episodes of seizures/hospitalization, previous treatment taken, significant points in family history, neurodevelopment history, socioeconomic history, findings on physical examination, laboratory investigations, and treatment details were noted on a pretested pro forma. The child's emotional and behavioral functioning at home were assessed by the Childhood Psychopathology Measurement Schedule (CPMS). ${ }^{7}$ This scale is an Indian adaptation of child behavior checklist, containing 75 items and is applicable to children between 4 and 14 years of age. The patient is assessed in eight domains, low intelligence, conduct disorder, anxiety, psychotic symptoms, depression, special symptoms, physical illness, and somatization. Children with CPMS score $>10$ are considered to have significant psychopathological abnormalities.

The assessment of socioeconomic status was done by modified Kuppuswamy scale (KS). ${ }^{8}$ It classifies socioeconomic status into five socioeconomic classes: upper (I), upper middle (II), lower middle (III), upper lower (IV), and lower $(\mathrm{V})$ on the basis of education, occupation of the head of the family, and total family income. KS class IV and V were taken as poor socioeconomic status.

\section{Statistical Analysis}

Continuous data was presented as mean (standard deviation [SD]) or median (interquartile range) and dichotomous data as percentage. The distribution of the data was tested by Kolmogorov-Smirnov test. For comparison of continuous data Student's $t$ test and Mann-Whitney test were used. Chi-square test or Fisher's exact test was used for comparing dichotomous data. We used multivariable logistic regression analysis to find independent predictors of high CPMS scores. Statistical analysis was done using SPSS Window software, version 18 .

\section{Results}

\section{Sociodemographic Details}

In this study, a total of 205 patients were enrolled, among them 135 (76 males) were CWE and 70 (44 males) controls. The mean \pm SD age of CWE was $9.7 \pm 2.91$ years while for controls it was $9.6 \pm 2.45$ years with no significant difference between the two groups ( $p$ 0.365). In the CWE group, $51(37.7 \%)$ patients belonged to poor socioeconomic status as compared with $24.2 \%$ in the control group. Higher number of patients belonged to rural area $(80.7 \%)$ in the epilepsy group ( $p$-value 0.003 ). In the epilepsy group, proportion of patients with significant family history of psychiatric illnesses (4.4\%), drug/alcohol addiction (28.8\%), and criminal background $(2.9 \%)$ were comparable to the control group (-Table $\mathbf{1}$ ).

\section{Clinical Details}

Developmental delay was seen in 11 (8\%) CWE patients, while none of the patients in the control group had developmental delay. Significant number (39\%) of CWE patients had poor academic performance as compared with the control group $(5.7 \%)$ ( $p$-value $<0.00001)$. More than half $(53 \%)$ patients in the CWE group had CPMS score $>10$ whereas in the control group this proportion was only $33 \%$. The mean CPMS score for the epilepsy group $(13.68 \pm 10.57)$ was significantly higher than the control group $(9.75 \pm 7.97)$ ( $p$-value 0.003). CWE had significantly higher mean (SD) scores in area of low intelligence $3.44 \pm 2.98$, conduct disorder $4.59 \pm 4.24$, depression $1.73 \pm 1.97$, and psychotic symptoms $0.78 \pm 1.22$, as compared with controls. However, both the groups did not differ significantly in anxiety, special symptoms, physical illness with emotional problems, and somatization scores (-Table 2 ). 
Table 1 Sociodemographic details of study groups

\begin{tabular}{|l|l|l|l|}
\hline & CWE $(\boldsymbol{n}=135)$ & Controls $(\boldsymbol{n}=\mathbf{7 0})$ & $\boldsymbol{p}$-Value \\
\hline Age, mean \pm SD, $y$ & $9.75 \pm 2.91$ & $9.68 \pm 2.45$ & 0.853 \\
\hline Males, $n(\%)$ & $76(56.2)$ & $44(62.8)$ & 0.365 \\
\hline Poor socioeconomic status, $n(\%)$ & $51(37.7)$ & $17(24.2)$ & 0.051 \\
\hline Urban residence, $n(\%)$ & $21(15.5)$ & $25(35.7)$ & 0.003 \\
\hline Migrants/natives, $n(\%)$ & $38(28.1)$ & $20(28.5)$ & 0.949 \\
\hline Psychiatric illness in family, $n(\%)$ & $6(4.4)$ & $8(11.4)$ & 0.600 \\
\hline Drug addiction/alcoholism in family, $n(\%)$ & $39(28.8)$ & $15(21.4)$ & 0.250 \\
\hline Family criminal background, $n(\%)$ & $4(2.9)$ & $1(1.4)$ & 0.500 \\
\hline
\end{tabular}

Abbreviations: CWE, children with epilepsy; SD, standard deviation.

Note: $p$-Values set in bold are statistically significant.

Table 2 Clinical details of CWE and controls

\begin{tabular}{|l|l|l|l|}
\hline & CWE $(\boldsymbol{n}=\mathbf{1 3 5})$ & Controls $(\boldsymbol{n}=\mathbf{7 0})$ & $\boldsymbol{p}$-Value \\
\hline Developmental delay, $n(\%)$ & $11(8)$ & $0(0)$ & \\
\hline Poor academic performance, $n(\%)$ & $53(39)$ & $4(6)$ & $<\mathbf{0 . 0 0 0 0 1}$ \\
\hline CPMS $>10, n(\%)$ & $72(53)$ & $23(33)$ & $\mathbf{0 . 0 0 5}$ \\
\hline CPMS, mean \pm SD & $13.68 \pm 10.57$ & $1.51 \pm 1.98$ & $\mathbf{0 . 0 0 3}$ \\
\hline Low intelligence, mean \pm SD & $3.44 \pm 2.98$ & $3.58 \pm 3.38$ & $<\mathbf{0 . 0 0 0 0 1}$ \\
\hline Conduct disorder, mean \pm SD & $4.59 \pm 4.24$ & $0.80 \pm 1.08$ & $\mathbf{0 . 0 4 3}$ \\
\hline Anxiety, mean \pm SD & $0.75 \pm 0.97$ & $0.51 \pm 0.84$ & 0.382 \\
\hline Psychotic symptoms, mean \pm SD & $0.78 \pm 1.22$ & $1.11 \pm 1.90$ & $\mathbf{0 . 0 4 9}$ \\
\hline Depression, mean \pm SD & $1.73 \pm 1.97$ & $0.44 \pm 0.86$ & $\mathbf{0 . 0 1 6}$ \\
\hline Special symptoms, mean \pm SD & $0.68 \pm 1.10$ & $0.50 \pm 0.88$ & 0.058 \\
\hline Physical illness, mean \pm SD & $0.66 \pm 0.84$ & $1.28 \pm 1.01$ & 0.094 \\
\hline Somatization, mean \pm SD & $1.03 \pm 1.49$ & 0.099 \\
\hline
\end{tabular}

Abbreviations: CPMS, Childhood Psychopathology Measurement Schedule; CWE, children with epilepsy; SD, standard deviation.

Note: $p$-Values set in bold are statistically significant.

\section{CWE Group}

We further divided the CWE group $(n=135)$ into two on the basis of CPMS scoring: 63 (47\%) patients had CPMS $\leq 10$ and 72 (53\%) CPMS > 10 (- Table 3). CWE with CPMS $>10$ had mean (SD) CPMS score of $19.88 \pm 10.98$ while CWE with CPMS $\leq 10$ had mean CPMS score of $6.58 \pm 2.39$. These two subgroups did not differ significantly in terms of age and gender distribution, type of residence, and socioeconomic status. The mean (SD) age of onset of epilepsy in both the groups was comparable, that is, $6.76 \pm 3.28$ and $7.11 \pm 3.46$ years in CPMS $\leq 10$ and CPMS $>10$ group, respectively. The mean \pm SD duration of epilepsy was $34.6 \pm 25.9$ months and mean \pm SD duration of AED therapy was $29.80 \pm 21.21$ months in CPMS $>10$ which did not differ significantly with the other group ( $p$-value 0.32 and 0.27 ). There was no difference in type and etiology of epilepsy and seizure recurrence in both the groups. Eleven (15\%) patients in CPMS $>10$ were on polytherapy compared with only $1.5 \%$ in the CPMS $\leq 10$ group ( $p$-value 0.005 ). In both the sub- groups, most commonly used AED was phenytoin while least commonly used drug was levetiracetam. The subgroups differed significantly in distribution of AEDs; higher proportion (32\%) of patients with CPMS $>10$ was on sodium valproate ( $p$-value 0.045$)$.

\section{Control Group}

Two subgroups were made in the control group $(n=70)$, CPMS $\leq 10(n=47)$ and CPMS $>10(n=23)$. Both subgroups did not differ significantly in terms of age, gender distribution, type of residence, socioeconomic status, academic performance, and family history of drug/alcohol addiction or psychiatric disorders (-Table 4).

\section{Predictive Factors for High CPMS Score}

The influence of various variables on high CPMS score was examined using multivariate logistic regression. CWE were 2.33 times (confidence interval $[\mathrm{CI}] 1.27,4.27$ ) more likely to have higher CPMS score than controls ( $p$ 0.005). Multiple AED 
304 Psychopathological Aspects in Children with Epilepsy and Its Contributing Factors Azad et al.

Table 3 Characteristics of children with epilepsy

\begin{tabular}{|c|c|c|c|}
\hline Variable & CPMS $\leq 10(n=63)$ & CPMS $>10(n=72)$ & $p$-Value \\
\hline Age, mean $\pm S D$, y & $9.47 \pm 2.62$ & $10 \pm 3.14$ & 0.149 \\
\hline Males, $n(\%)$ & $36(57)$ & $40(55.5)$ & 0.398 \\
\hline Poor socioeconomic status, $n(\%)$ & $22(35)$ & $28(39)$ & 0.633 \\
\hline Urban residence, $n(\%)$ & $7(11)$ & $14(19)$ & 0.151 \\
\hline Poor academic performance, $n(\%)$ & $19(30)$ & $34(47)$ & 0.042 \\
\hline CPMS score, mean \pm SD & $6.58 \pm 2.39$ & $19.88 \pm 10.98$ & $<0.00001$ \\
\hline Age at onset of epilepsy, mean $\pm S D, y$ & $6.76 \pm 3.28$ & $7.11 \pm 3.46$ & 0.264 \\
\hline $\begin{array}{l}\text { Duration of epilepsy, } \\
\text { mean } \pm S D \text {, mo }\end{array}$ & $32.53 \pm 27.25$ & $34.60 \pm 25.86$ & 0.326 \\
\hline Generalized seizures, $n(\%)$ & $34(54)$ & $36(50)$ & 0.64 \\
\hline Symptomatic epilepsy, n (\%) & $33(52)$ & $38(53)$ & 0.963 \\
\hline Duration of AED, mean $\pm S D$, mo & $27.61 \pm 21.48$ & $29.80 \pm 21.21$ & 0.277 \\
\hline Polytherapy, n (\%) & $1(1.5)$ & $11(15)$ & 0.005 \\
\hline \multicolumn{4}{|l|}{ Antiepileptic drugs } \\
\hline Phenytoin, $n(\%)$ & $43(68)$ & $34(47)$ & \multirow[t]{5}{*}{0.045} \\
\hline Sodium valproate, $n(\%)$ & 12 (19) & $31(43)$ & \\
\hline Levetiracetam, n (\%) & 0 & $4(5.5)$ & \\
\hline Carbamazepine, $n(\%)$ & $7(11)$ & $11(15)$ & \\
\hline Benzodiazepines, $n$ (\%) & $2(3)$ & $5(7)$ & \\
\hline \multicolumn{4}{|l|}{ Seizure recurrence } \\
\hline Weekly, n (\%) & 3 & 5 & \multirow[t]{3}{*}{0.231} \\
\hline Monthly, n (\%) & 2 & 7 & \\
\hline Yearly/no recurrence, $n$ (\%) & 60 & 60 & \\
\hline
\end{tabular}

Abbreviations: AED, antiepileptic drug; CPMS, Childhood Psychopathology Measurement Schedule; SD, standard deviation.

Note: $p$-Values set in bold are statistically significant.

Table 4 Characteristics of control group

\begin{tabular}{|l|l|l|l|}
\hline & CPMS $\leq 10(N=47)$ & CPMS $>10(N=23)$ & $p$-Value \\
\hline Age, mean \pm SD, $y$ & $9.54 \pm 2.37$ & $9.96 \pm 2.65$ & 0.253 \\
\hline Males, $n(\%)$ & $27(57)$ & $18(78)$ & 0.087 \\
\hline Poor socioeconomic status, $n(\%)$ & $12(25.5)$ & $6(26)$ & 0.567 \\
\hline Rural residence, $n(\%)$ & $32(68)$ & $12(52)$ & 0.156 \\
\hline Poor academic performance, $n(\%)$ & $2(4)$ & $2(9)$ & 0.323 \\
\hline Alcoholism/drug addiction in family, $n(\%)$ & $8(17)$ & $7(30)$ & 0.198 \\
\hline Psychiatric disorders in family, $n(\%)$ & $5(11)$ & $3(13)$ & 0.766 \\
\hline CPMS score, mean \pm SD & $5.25 \pm 2.18$ & $18.95 \pm 7.58$ & $<\mathbf{0 . 0 0 0 0 1}$ \\
\hline
\end{tabular}

Abbreviations: CPMS, Childhood Psychopathology Measurement Schedule; SD, standard deviation.

Note: $p$-Values set in bold are statistically significant.

therapy increased the likelihood of higher CPMS scores to 11.18 times (CI 1.40, 89.26) as compared with monotherapy ( $p$ 0.022). Sodium valproate when compared with phenytoin had 3.26 times more odds of having associated with high CPMS scores ( $p$ 0.001) (-Table 5). Poor socioeconomic status (KS IV/V) and place of residence did not prove to be a significant predictor of poor CPMS score ( $p 0.243$ and 0.135 ).

\section{Discussion}

The present study showed high prevalence (53\%) of psychopathological problems in 135 (63\% males) CWE of 4 to 14 years age group as compared with controls (33\%). Thirty-nine percent CWE had poor academic performance as compared with only $6 \%$ of controls. CPMS scores were significantly high in 
Table 5 Predictive factors for poor CPMS score

\begin{tabular}{|c|c|c|c|c|}
\hline & $\begin{array}{l}\text { CPMS }<10 \\
n(\%)\end{array}$ & $\begin{array}{l}\text { CPMS }>10 \\
n(\%)\end{array}$ & $\begin{array}{l}\text { Odds ratio } \\
(95 \% \mathrm{Cl})\end{array}$ & $p$-Value \\
\hline \multicolumn{5}{|l|}{ Socioeconomic class } \\
\hline $\mathrm{KS} I \mathrm{~V} / \mathrm{V}(n=68)$ & $34(50)$ & $34(50)$ & $1.24(0.69-2.23)$ & \multirow[t]{2}{*}{0.45} \\
\hline $\mathrm{KS} \mathrm{I/III}(n=137)$ & $76(55)$ & $61(45)$ & Ref & \\
\hline \multicolumn{5}{|l|}{ Residence } \\
\hline Urban $(n=47)$ & $22(47)$ & $25(53)$ & $1.42(0.74-2.74)$ & \multirow[t]{2}{*}{0.28} \\
\hline Rural $(n=158)$ & $88(56)$ & $70(44)$ & Ref & \\
\hline Epilepsy $(n=135)$ & $63(47)$ & $72(53)$ & $2.33(1.27-4.27)$ & 0.005 \\
\hline Control $(n=70)$ & $47(67)$ & $23(33)$ & Ref & \\
\hline Polytherapy $(n=12)$ & $01(8)$ & $11(92)$ & $11.18(1.40-89.26)$ & \multirow[t]{2}{*}{0.022} \\
\hline Monotherapy $(n=123)$ & $62(50.4)$ & $61(49.6)$ & Ref & \\
\hline Sodium valproate $(n=43)$ & $12(28)$ & $31(72)$ & $3.26(1.46-7.3)$ & \multirow[t]{2}{*}{0.003} \\
\hline Phenytoin $(n=77)$ & $43(56)$ & $34(44)$ & Ref & \\
\hline
\end{tabular}

Abbreviations: Cl, confidence interval; CPMS, Childhood Psychopathology Measurement Schedule; KS, Kuppuswamy scale. Note: $p$-Values set in bold are statistically significant.

low intelligence, conduct disorder, depression, and psychotic symptoms domains. There was significant association of polytherapy and valproate with psychopathological issues $(p 0.022$ and 0.001 ).

As per literature, psychopathology occurs in 35 to $75 \%$ of CWE, and problems associated with attention, thought, and internalization problems might be specific to epilepsy. ${ }^{9-11}$ Poor cognition, language problems, and family factors may affect psychopathology in CWE.

Various studies concluded that onset and duration of epilepsy and its treatment does not have significant impact in CWE with normal intelligence. Present study also demonstrated no significant association with type of seizures, etiology of epilepsy, age of onset, or duration of epilepsy or duration of AED with prevalence of psychopathological problems in CWE.

Guilfoyle et el reported higher chances of AED behavioral side effects in children as compared with adolescents in newonset epilepsy. These side effects were highest with valproic acid; levetiracetam was another drug which exhibited high behavioral side effects. ${ }^{12}$

Present study also demonstrated significant correlation of valproic acid with psychopathological issues. Children on polytherapy experience significantly more anxiety and depression as compared with children on monotherapy. ${ }^{13}$ We also found polytherapy as a predictive factor for higher CPMS scores.

Singh et al observed that $36 \%$ CWE between the ages of 6 and 16 years of age had poor academic performance and $47 \%$ had psychopathological illnesses, these were significantly higher than in another common chronic disorder asthma. ${ }^{14}$ In the present study, 39\% parents of CWE reported poor academic performance. Various factors like comorbid psychopathology, parental overprotection, low self-esteem, and drug-related factors could be responsible for it.

In various studies, poor socioeconomic status was associated with higher incidence of psychopathology but in our study we did not find any such association., ${ }^{5,15}$ One reason could be higher proportion of poor socioeconomic status in the study; as being a government institute we mostly cater to poor population.

Family factors like drug addiction/alcoholism, psychiatric problems, or criminal background had no significant effect on psychopathology in the present study. In a systematic review it was observed that high percentage of children of parents with addiction might adapt to stress in life and show positive development in mental health domain because of various protective factors. ${ }^{16}$ However, parental criminal offending can lead to vulnerability in various domains in children especially in the cognitive sector. ${ }^{17}$ The present study had very low proportion (only 4 patients in CWE and 1 in the control group) of patients with parental criminal background so conclusions are not generalizable.

Present study excluded CWE with cerebral palsy and significant intellectual disability, thus results are not generalizable to them.

To conclude, psychopathological problems are fairly common in CWE and AEDs are an important contributing factor. Clinicians should incorporate psychopathological assessment in workup of CWE for holistic management.

\section{Authors' Contributions}

C.A.: conceptualization, data collection, literature search, and manuscript writing. V.G.: conceptualization, literature search, and manuscript writing; S.S.: Conceptualization, literature search, and manuscript writing; and A.S.: conceptualization, literature search, and manuscript writing.

\section{Funding}

This study was funded by the Department of Science and Technology, Chandigarh. 
306 Psychopathological Aspects in Children with Epilepsy and Its Contributing Factors Azad et al.

\section{Conflict of Interest \\ None declared.}

\section{References}

1 Amudhan S, Gururaj G, Satishchandra P. Epilepsy in India I: epidemiology and public health. Ann Indian Acad Neurol 2015; 18(03):263-277

2 Gadgil P, Udani V. Pediatric epilepsy: the Indian experience. J Pediatr Neurosci 2011;6(Suppl 1):S126-S129

3 Kariuki SM, Newton CRJC, Prince MJ, Das-Munshi J. The association between childhood seizures and later childhood emotional and behavioral problems: findings from a nationally representative birth cohort. Psychosom Med 2016;78(05):620-628

4 Kar S. Psychiatric aspects of pediatric epilepsy: focus on anxiety disorder. Med J Dr Patil Univ 2015;8(04):425

5 Khalid A, Aslam N. Psychological distress among patients with epilepsy. Indian J Psychol Med 2011;33(01):45-48

6 Murali V, Oyebode F. Poverty, social inequality and mental health. Adv Psychiatr Treat 2004;10(03):216-224

7 Malhotra S, Varma VK, Verma SK, Malhotra A. Childhood psychopathology measurement schedule: development and standardization. Indian J Psychiatry 1988;30(04):325-331

8 Sharma R. Revised Kuppuswamy's socioeconomic status scale: explained and updated. Indian Pediatr 2017;54(10):867-870

9 Plioplys S, Dunn DW, Caplan R. 10-year research update review: psychiatric problems in children with epilepsy. J Am Acad Child Adolesc Psychiatry 2007;46(11):1389-1402
10 Pellock JM. Defining the problem: psychiatric and behavioral comorbidity in children and adolescents with epilepsy. Epilepsy Behav 2004;5(Suppl 3):S3-S9

11 Baker GA, Spector S, McGrath Y, Soteriou H. Impact of epilepsy in adolescence: a UK controlled study. Epilepsy Behav 2005;6(04): 556-562

12 Guilfoyle SM, Follansbee-Junger K, Smith AW, et al. Antiepileptic drug behavioral side effects and baseline hyperactivity in children and adolescents with new onset epilepsy. Epilepsia 2018;59(01): 146-154

13 Plevin D, Jureidini J, Howell S, Smith N. Paediatric antiepileptic polytherapy: systematic review of efficacy and neurobehavioural effects and a tertiary centre experience. Acta Paediatr 2018;107 (09):1587-1593

14 Singh H, Aneja S, Unni KES, Seth A, Kumar V. A study of educational underachievement in Indian children with epilepsy. Brain Dev 2012;34(06):504-510

15 Elliott JO, Charyton C, Lu B, Moore JL. Serious psychological distress and health outcomes for persons with epilepsy in poverty. Seizure 2009;18(05):332-338

16 Wlodarczyk O, Schwarze M, Rumpf H-J, Metzner F, Pawils S. Protective mental health factors in children of parents with alcohol and drug use disorders: a systematic review. PLOS ONE 2017;12(06):e0179140

17 Laurens KR, Tzoumakis S, Kariuki M, et al. Pervasive influence of maternal and paternal criminal offending on early childhood development: a population data linkage study. Psychol Med 2017;47(05):889-901 